\title{
CIDADE, CULTURA E ACESSIBILIDADE: NOTAS INICIAIS DA RELAÇÃO ENTRE CIDADES EDUCADORAS E DIREITOS HUMANOS
}

\section{CITY, CULTURE AND ACCESSIBILITY: INITIAL NOTES ON THE RELATIONSHIP BETWEEN EDUCATING CITIES AND HUMAN RIGHTS}

\section{CIUDAD, CULTURA Y ACCESIBILIDAD: NOTAS INICIALES SOBRE LA RELACIÓN ENTRE CIUDADES EDUCADORAS Y DERECHOS HUMANOS}

\author{
Gabriela Sousa Ribeiro \\ Karoline Alves da Silva ${ }^{2}$ \\ Matheus Trindade Coelho da Silva ${ }^{3}$ \\ Thaynnara de Farias Pinto ${ }^{4}$
}

\begin{abstract}
Resumo
Ao considerar as premissas das cidades educadoras e dos direitos humanos, buscamos refletir ${ }^{5}$ sobre como as cidades podem ser vetores educacionais à ampla gama populacional, independentemente de suas características antropométricas, sensoriais, cognitivas, etárias etc. Para isso, entendemos que os preceitos do direito à cidade, da acessibilidade integral e do design universal são fundamentais para possibilitar que cidadãos realmente incluídos na dinâmica citadina possam vivenciar sua cidade, auxiliar a construí-la e aprender e ensinar constantemente com esse processo de vivência de seu território, de sua cultura, de sua identidade. É objetivo deste artigo problematizar em que medida a acessibilidade plena às pessoas com deficiência aos espaços citadinos, principalmente aos espaços culturais, contribui para uma educação holística de ampla gama populacional possibilitada pelas trocas de experiências e conhecimentos entre pessoas distintas e entre ambientes diversos, reafirmando seus direitos humanos pela possibilidade de vivenciar seu direito à cidade. Para isso, foram realizadas pesquisas bibliográficas e documentais com sua análise crítica. A retroalimentação entre acessibilidade, direito à cidade e cidade educadora se dá na construção diária e cotidiana de vidas dignas, de subjetividades possíveis, de diversidades respeitadas, vozes ouvidas e demandas alcançadas.
\end{abstract}

Palavras-chave: Direito à cidade. Acessibilidade. Cultura. Cidades educadoras.

\footnotetext{
1 Professora e pesquisadora do Instituto Federal de Educação, Ciência e Tecnologia do Rio de Janeiro (IFRJ). Doutora em Urbanismo (PROURB/UFRJ), Mestre em Design (PPGDesign/UFPE), Bacharel em Desenho Industrial (UFMA). Líder do Grupo de Pesquisa Território, Cultura e Identidade, certificado pelo IFRJ/CNPq. E-mail: gabriela.ribeiro@ifri.edu.br, gabrielasousaribeiro@gmail.com. ORCID: http://orcid.org/0000-0001-5003-8101.

2 Técnica em Produção de Moda (IFRJ), Graduanda em Design (PUC-Rio). Membro do Grupo de Pesquisa Território, Cultura e Identidade, certificado pelo IFRJ/CNPq. E-mail: klinealves@yahoo.com.br. ORDIC: https://orcid.org/0000-0001-6101-1916.

3 Graduando em Produção Cultural (IFRJ). Membro do Grupo de Pesquisa Território, Cultura e Identidade, certificado pelo IFRJ/CNPq. E-mail: mtrindade1996@gmail.com. ORDIC: https://orcid.org/0000-0003-4806-767X.

${ }^{4}$ Graduanda em Design Gráfico (Universidade Cruzeiro do Sul Virtual); Estudante do curso técnico em Produção de Moda (IFRJ). Membro do Grupo de Pesquisa Território, Cultura e Identidade, certificado pelo IFRJ/CNPq. Email: thaynnaradefarias@outlook.com. ORDIC: https://orcid.org/0000-0002-8508-1908.

${ }^{5} \mathrm{O}$ artigo é decorrente da pesquisa "Acessibilidade e direito à cidade: caminhos para uma cidade educadora", Coordenado pela profa. Gabriela Sousa Ribeiro e desenvolvido no Instituto Federal de Educação, Ciência e Tecnologia do Rio de Janeiro (IFRJ) campus Belford Roxo, com fomento da Pró-Reitoria de Pesquisa, Inovação e Pós-Graduação do IFRJ, a qual agradecemos.
} 


\begin{abstract}
Considering the concept of educating cities and human rights, we seek to reflect on how cities can be intermediaries of education to a wide demographic, regardless it's anthropometric, sensory, cognitive or age characteristics. For this, we understand that the propositions of the right to the city, integral accessibility and universal design are essential to make it possible for citizens, truly included at the city's dynamics, to experience their city, help to build it, and constantly learn and teach with the process of experiencing their territory, culture and identity. The goal of this article is to discuss how the integral accessibility of diseable people at urban spaces, mostly at the culture related ones, contributes to a holistic education for a wide range, made possible by the exchanges of experiences and knowledge among different people and different places, reaffirming their human rights by the possibility of practicing their right to the city. With that in mind, there were made literature and documentary reviews, with critical analysis of them. The association among accessibility, right to the city and educating cities happens everyday at the construction of dignified lives, of possible subjectivities, respected diversity, voices heard and demands achieved.
\end{abstract}

Keywords: Right to the city. Accessibility. Culture. Educating cities.

\title{
Resumen
}

Al considerar las premisas de las ciudades educadoras y los derechos humanos, tratamos de reflexionar sobre como las ciudades pueden ser vectores educativos para la amplia gama de la población, sin importar sus características antropométricas, sensoriales, cognitivas, de edad, etc. Con este fin, comprendemos que los preceptos del derecho a la ciudad, accesibilidad integral y diseño universal son fundamentales para permitir a los ciudadanos realmente incluidos en la dinámica de la ciudad experimentar su ciudad, ayudar a construirla y aprender y enseñar constantemente con este proceso de vivir su territorio, su cultura, su identidad. El objetivo de este artículo es problematizar en que medida la accesibilidad plena de las personas con discapacidad a los espacios de la ciudad, especialmente los espacios culturales, contribuye a una educación holística de una amplia gama de población que es posible gracias al intercambio de experiencias y conocimientos entre diferentes personas y entre diferentes entornos, reafirmando sus derechos humanos por la posibilidad de experimentar su derecho a la ciudad. Para esto, se realizó una investigación bibliográfica y documental con análisis crítico. La retroalimentación entre accesibilidad, derecho a la ciudad y a ciudad educadora se produce en la construcción diaria de vidas dignas, subjetividades posibles, diversidades respetadas, voces escuchadas y demandas alcanzadas.

Palabras clave: Derecho a la ciudad. Accesibilidad. Cultura. Ciudades educadoras.

\section{INTRODUÇÃO}

Ao examinarmos a Declaração Universal dos Direitos Humanos (UNIC RIO, 2009), vemos citações no artigo XIX ao "direito à liberdade de opinião e expressão" (op. cit., p. 10). No artigo XXI, ao "direito de fazer parte no governo de seu país diretamente ou por intermédio de representantes livremente escolhidos" e ao "direito de acesso ao serviço público do seu país" (op. cit., p. 11). O artigo XXII entende todo ser humano como membro da sociedade e, por isso, deve usufruir dos "direitos econômicos, sociais e culturais indispensáveis à sua dignidade e ao livre desenvolvimento da sua personalidade" (op. cit., p.12). O artigo XXIV assegura o direito ao repouso e lazer. No artigo XXVI diz que "todo ser humano tem direito à instrução" (op. cit., p. 14). A todo ser humano, "o direito de participar livremente da vida cultural da comunidade, de fruir das artes e de participar do progresso científico e de seus benefícios" está descrito no artigo XXVII (op. cit., p. 14 e 15). 
Os artigos mencionados mostram que, para assegurar os direitos humanos, há necessidade de relação constante entre educação, cultura, lazer e participação social. E, para efetivar essa relação, a vida na e da cidade se faz necessária.

Ao pensarmos na educação num sentido holístico, partimos do pressuposto de que, seja pobre ou rica, grande ou pequena, toda cidade, enquanto palco de encontros e de trocas socioculturais constantes, pode contribuir para educar as pessoas. É nesse sentido que se configuram as premissas das cidades educadoras.

As cidades assumidas como cidades educadoras trabalham para transformar a utopia de uma cidade, educar e ser educada pelos cidadãos em realidade, através de novas formas de participação nas decisões coletivas, praticando e incentivando o exercício da construção dos consensos necessários para a vida de todos os habitantes ter mais dignidade e qualidade (MORIGI, 2014, p. 8).

Eduardo Galeano (1998) nos fala que a utopia serve para que não paremos nunca de caminhar, de correr atrás dela. Seria utópico pensar em cidades periféricas, como, por exemplo, os municípios da Baixada Fluminense, com carência de infraestrutura urbana, baixa taxa de escolaridade de seus habitantes e altos índices de violência, como cidades em que é possível conviver nos espaços citadinos, participar da vida na e da cidade e construir junto com a sociedade a cidade desejada, aprendendo e ensinando com isso?

A primeira Carta das Cidades Educadoras foi lançada, em 1990, em Barcelona. Desde esse período até a atualidade, decorrentes das próprias transformações sociais, culturais, espaciais e tecnológicas no mundo, mudanças foram incorporadas em suas publicações atualizadas em 1994 e 2004 (AICE, 2019). Ao analisar projetos de cidades educadoras ao longo do mundo, observamos as mais diversas cidades, pobres, ricas, grandes, pequenas, brasileiras, estrangeiras, conseguindo ou buscando alcançar premissas colocadas na Carta.

Entre as brasileiras, há cidades localizadas nos estados de São Paulo, Minas Gerais, Espírito Santo e Rio Grande do Sul. As cidades não apresentam similaridades no que se refere aos contingentes populacionais, porém, no que concerne ao Índice de Desenvolvimento Humano Municipal (IDHM), conforme o Atlas do Desenvolvimento Humano no Brasil (2013), estão enquadradas entre as classificações alto e muito alto. No estado de São Paulo estão: Guarulhos (1.221.979 habitantes e IDHM 0,763), Mauá (417.064 habitantes e IDHM 0,776), Sorocaba (586.625 habitantes e IDHM 0,798), São Paulo (11.253.503 habitantes e IDHM 0,805), São Bernardo do Campo (765.463 habitantes e IDHM 0,805), São Carlos (221.950 habitantes e IDHM 0,805), Santo André (676.407 habitantes e IDHM 0,815) e Santos $(419.400$ habitantes e IDHM 0,840). No estado de Minas Gerais, está Belo Horizonte, com 2.375.151 habitantes e IDHM 0,810. No estado do Espírito Santo, Vitória tem 327.801 habitantes com 
IDHM 0,845. No estado do Rio Grande do Sul participam as cidades de Porto Alegre (1.409.351 habitantes e IDHM 0,805), Caxias do Sul (435.564 habitantes e IDHM 0,782) e Nova Petrópolis (19.045 habitantes e IDHM 0,780) (AICE, 2019; AIETA; ZUIN, 2012; ATLAS BRASIL, 2013).

No estado do Rio de Janeiro, mais especificamente na Baixada Fluminense, o município de Nova Iguaçu desenvolveu o projeto Bairro-Escola, concernente aos princípios da cidade educadora. Vaz et al. (2012) analisaram o projeto, que buscava, principalmente, propiciar melhorias na ambiência urbana e na qualidade de vida dos habitantes, articulando as esferas educacional, urbana e cultural. A proposta inferia "a necessidade de participação de diferentes atores e setores da administração municipal e da sociedade civil, formando redes nas quais o espaço urbano se torna peça fundamental em uma estratégia de forte viés social" (op. cit., p. 52). Ainda que tenha sido um projeto descontinuado em função das trocas políticas atuantes do município, os autores contam que

o mérito do Bairro-Escola passa pelos valores e princípios que o fundamentam. Por propor um diálogo com o real, processos participativos e uma integração entre esferas diversas, ele constitui uma política ampla e intrincada, que sugere uma nova tendência na elaboração de políticas públicas no Brasil. Mais do que isso, ela anuncia projetos e programas que, conjuntamente, apresentam potencial estruturante de transformações sociais (VAZ et al., 2012, p. 67).

A utopia em torno da vivência da e na cidade é permeada pela constante disputa de forças verticais e horizontais. Conforme Santos (2009, 2001), o poder vertical é advindo dos detentores do domínio do capital, do Estado e das demais forças atuantes de cima para baixo, visando impor seu pleito no espaço das forças horizontais. Estas são caracterizadas pela organização entre iguais (ou parecidos) que buscam se juntar para ter voz e alcançar suas demandas na cotidianidade do território. Para Santos (2009), as pressões decorrentes das disputas de poder internas e externas são permeadas por vários aspectos, englobando as configurações do território, as ações sobre ele e as forças políticas nele incidentes.

No que se refere às forças e disputas políticas, corroboramos com Lefebvre (2010), que argumenta sobre a acepção do termo político tomado numa abordagem ampla, que não se trata nem das ambições das disciplinas parciais, muito menos no que se refere à luta partidária.

A disputa cotidiana pelo território se concretiza na potência dos habitantes de cidades periféricas e pobres. Ponderamos que, enquanto essas cidades se mostram carentes de urbanização, seus habitantes mostram-se potentes. Cotidianamente, é preciso muita potência para sobreviver e transformar suas realidades. Corroboramos com Santos $(2009,2001)$ e com Certeau (2008), que reconhecem o valor das construções cotidianas dos homens lentos 
(SANTOS, 2009; 2001) e ordinários (CERTEAU, 2008), a partir de seus saberes, fazeres, costumes, práticas e vivências da e na cidade.

O enfoque de Certeau (2008) abre novas formas de olhar e compreender os espaços a partir das pequenas operações cotidianas que originam as práticas sociais daqueles que os habitam. Estas práticas empreendidas pelas populações são pouco evidentes, dispersas, muitas vezes silenciosas, todavia, revelam maneiras astutas de reapropriação do espaço. São as diferentes formas de reorganizar o cotidiano de suas práticas; do âmbito do que poderíamos chamar dessas microrresistências pode emergir uma condição urbana e uma qualidade de vida não preconizadas nem capturadas pelas políticas públicas. Na Baixada Fluminense, no município de Belford Roxo, com carência de ofertas culturais institucionalizadas, podemos citar as sessões de cineclube no Espaço Cultural Donana, a roda de rap na Praça de Heliópolis e a Feira de Areia Branca, que iniciou sua existência na rua de forma espontânea com a venda de produtos ao consumo cotidiano, como frutas, verduras, artesanatos, mas que também apresenta contradições, como o comércio ilegal de animais silvestres no local. Ainda assim, a feira cresceu tanto que forçou a governança municipal a intervir no espaço urbano, de modo que possa ocorrer com mais conforto e segurança para os frequentadores.

Santos (2009) pondera que as horizontalidades são caracterizadas e conformadas na cotidianidade dos homens lentos, enquanto as verticalidades se dão nas esferas de poder daqueles que impõem os espaços luminosos, longe da ação dos primeiros.

Podemos afirmar que a disputa em torno do território, das manifestações horizontais e de sua potência têm relação com a educação cotidiana vivenciada na e pela cidade. No mesmo sentido, Morigi (2014) afirma que a educação é um processo para a vida toda, que deve acontecer em todas as fases da vida e em todo lugar. "Qualquer local é espaço de aprendizagem. Isso passa por uma socialização dos saberes e pelo reconhecimento de que todos os indivíduos são potenciais educadores, cada um em sua especialidade, em sua sabedoria de vida" (MORIGI, 2014, p. 23 e 24).

As afirmações do autor vão ao encontro de algumas premissas das cidades educadoras (AICE, 2019): o direito a uma cidade que deverá promover uma educação integradora, uma "educação que deverá combater toda a forma de discriminação" (AICE, 2019, p. 4); o compromisso do governo municipal em financiar espaços, equipamentos e serviços públicos para o desenvolvimento pessoal, social, moral e cultural dos habitantes; bem como fiscalizar esses serviços, pois o "município deverá avaliar o impacto das ofertas culturais, recreativas, informativas, publicitárias" (AICE, 2019, p. 7). 
Ponderamos então que educação envolve muito mais do que a escola e a sala de aula. A sabedoria da vida, conforme disse Morigi (2014), é o que faz com que a população periférica consiga sobreviver em seus espaços banais e opacos, (re)inventar seus modos de fazer e propagar sua identidade, sua cultura, sua memória, sua potência.

Toda essa discussão corrobora com os preceitos defendidos por Lefebvre (2010, p. 134) no que tange ao direito à cidade, que "se manifesta como forma superior dos direitos: direito à liberdade, à individualização na socialização, ao habitat e ao habitar. O direito à obra (à atividade participante) e o direito à apropriação (bem distinto do direito à propriedade) estão implicados no direito à cidade".

Esse direito à cidade é visto numa perspectiva mais ampla, de apropriação da obra. Não apenas no que se refere a conseguir ter uma rua asfaltada ou uma parada de ônibus em determinado local. É algo em que essas conquistas estão incluídas também, mas estão muito além disso. É a possibilidade de apreender, usar, moldar, fruir, viver a cidade como um todo. Diz respeito à vida cotidiana na cidade, uma cidade feita e conservada com vistas ao valor da fruição, da experiência, da satisfação, da festa, dos encontros, das trocas interpessoais, das trocas população-espaços públicos e das manifestações socioculturais. Ou seja, do processo ensino-aprendizagem mútuo e constante, da possibilidade, então, de vivenciar e propagar a cultura da população no território. Este é entendido como o espaço vivenciado pelos cidadãos a partir de seus aspectos socioculturais, que fazem com que se sintam convidados à experiência e fruição do e no mesmo, nos termos de Santos (2009) e Haesbaert (2007). Este último autor relaciona o conceito de território ao de identidade. Para ele, esses conceitos se conformam a partir da experiência, que é necessariamente social.

Consideramos importante lembrar, então, que o debate sobre cultura é também um debate em torno de disputa política. Quando falamos de memória, território, identidade, o embate político já se faz implícito pela constante luta entre forças verticais e horizontais (SANTOS, 2009) que se articulam no espaço. Para Lefebvre (2010), essa disputa política tem relação direta com o direito à cidade.

Fato é que esse processo ainda é negado à maioria da população, seja a das grandes cidades brasileiras, seja a das menores e, principalmente, as de cidades periféricas e pobres. Vaz et al. (2012) ponderam que, se comparadas com as áreas centrais privilegiadas, raras são as políticas públicas voltadas para a periferia. Afirmam que, quando existem, são pontuais e, muitas vezes, de caráter eleitoreiro, evidenciando a predominância de políticas parciais e setoriais, o que reforça a desigualdade em termos de desenvolvimento urbano. 
Dentro dessa discussão, há ainda um grupo de pessoas que tem seu direito à cidade ainda mais negado, as pessoas com deficiência.

Ao considerar as premissas das cidades educadoras e dos direitos humanos, buscamos refletir sobre como as cidades podem ser espaços onde haja oferta de cultura acessível a todos, de modo que a cultura seja vetor educacional a ampla gama da população, independentemente de suas características antropométricas, sensoriais, cognitivas, etárias etc. Para isso, entendemos que os preceitos do direito à cidade (LEFEBVRE, 2010), da acessibilidade integral (SASSAKI, 2003) e do design universal (CAMBIAGHI, 2007; STORY, 2001) são fundamentais para possibilitar que cidadãos realmente incluídos na dinâmica citadina possam vivenciar sua cidade, auxiliar a construí-la e aprender e ensinar constantemente com esse processo de vivência de seu território, de sua cultura, de sua identidade.

Desenvolver pesquisas que relacionem os aspectos do direito à cidade às questões de acessibilidade plena, entendendo que possibilitar acesso e usufruto amplos e irrestritos aos espaços citadinos contribuem para o incremento da inclusão social, propiciando uma formação holística cidadã e reverberando na consolidação dos direitos humanos, é essencial na busca por uma sociedade melhor. "Nessa conjuntura, não se trata de tentar simplesmente analisar a cidade, mas de interpretar os discursos por ela produzidos, que marcam suas relações com seus habitantes" (AIETA; ZUIN, 2012, p. 216).

Diante do exposto, é objetivo deste artigo problematizar em que medida a acessibilidade plena às pessoas com deficiência aos espaços citadinos, principalmente aos espaços culturais, contribui para uma educação holística de ampla gama populacional possibilitada pelas trocas de experiências e conhecimentos entre pessoas distintas e entre ambientes diversos, reafirmando seus direitos humanos pela possibilidade de vivenciar seu direito à cidade.

Vale ressaltar que o conceito de cultura adotado neste trabalho não se restringe a manifestações culturais institucionalizadas, nem muito menos turistificadas, assim como não nos referimos apenas a espaços culturais institucionalizados, nem vendáveis. A cultura defendida neste trabalho engloba também esses aspectos, mas é entendida de modo mais amplo. Nos termos de Geertz (2012), defendemos o conceito de cultura como tido na atualidade, entendido como "estilo de vida de um povo". Sendo, portanto, a vivência na e da cidade um dos espaços principais para as manifestações dessas culturas.

\section{PESSOAS COM DEFICIÊNCIA E CULTURA}


Apesar de, conforme o Censo 2010 (IBGE, 2012), 23,9\% da população brasileira apresentarem algum tipo de deficiência, nossas cidades ainda não são preparadas para que essas pessoas possam ter seus direitos e suas vivências na cidade efetivados. Assim, o que as cidades "falam" a essas pessoas é que elas não são, ou não deveriam ser, pertencentes às urbes, falas essas inadmissíveis, que rechaçamos e queremos contribuir para reverter.

A Organização Mundial de Saúde estima que, em tempos de paz, em torno de 10\% da população dos países desenvolvidos seja constituída por pessoas que apresentam algum tipo de deficiência; enquanto nos países em desenvolvimento esse percentual sobe para 12 a $15 \%$. Nos primeiros, as causas mais frequentes são provenientes de guerras. Nas nações em desenvolvimento, como o Brasil, o índice elevado deve-se, em grande parte, aos acidentes de trânsito, à violência urbana, à falta de segurança no trabalho, à falta de assistência à mulher na gravidez, à desnutrição, à carência alimentar e, ainda, à falta de condições de higiene e a aspectos relacionados à miséria. Realidades presentes na vida das populações dos municípios mais pobres e das periferias brasileiras, de modo geral.

Dorneles et al. (2018) destacam o círculo vicioso entre pobreza e deficiência. Analisam que o risco maior das pessoas pobres adquirirem algum tipo de deficiência se dá em função do pouco acesso à boa alimentação, aos serviços de saúde e de saneamento, que, entre outros, geram problemas no desenvolvimento das pessoas. Corpos com algum tipo de restrição têm menos possibilidade de derrubar as barreiras impostas à população, gerando esse círculo vicioso: "a deficiência tem levado barreiras à educação, ao emprego, e aos serviços públicos que poderiam contribuir para tirar as pessoas com deficiência da pobreza" (DORNELES et al., 2018, p. 140).

Somados a isso, salientamos sobre a tendência de que, com o avanço da idade, o corpo vai gradualmente perdendo suas capacidades físicas, mentais e sensoriais, fazendo com que a proporção da deficiência aumente com a idade, passando de 4,3\% nas crianças até 14 anos para $54 \%$ do total das pessoas com idade superior a 65 anos. Logo, considerando a expectativa de vida média do brasileiro de 75,5 anos (PORTAL BRASIL, 2016), estimamos que as pessoas ainda poderão viver cerca de 15 anos de suas vidas com algum tipo de deficiência.

Portanto, pensar a acessibilidade de modo amplo, não apenas com enfoque nas condições arquitetônicas, contribui para a melhoria da qualidade de vida de toda a população; além de ser um direito respaldado na legislação brasileira e nas cortes internacionais de direitos humanos. 
Entendemos que a acessibilidade plena é possibilitada quando, de forma satisfatória e equitativa, são incorporadas à sociedade os seis tipos de acessibilidades descritas por Sassaki (2003). São elas: acessibilidade física ou arquitetônica (tem relação com eliminação de barreiras físicas, tanto em ambientes privados, como habitações, como em espaços coletivos e públicos); acessibilidade comunicacional (busca eliminar barreiras nas comunicações interpessoal, escrita, oral e visual); acessibilidade metodológica (pretende acabar com as barreiras nos métodos e técnicas de estudo, de trabalho, de ação comunitária e de educação de modo amplo); acessibilidade instrumental (visa eliminar barreiras nos instrumentos e utensílios de estudo, de trabalho, de atividades da vida diária, de cultura, de lazer e de esporte); acessibilidade programática (busca eliminar barreiras invisíveis embutidas em políticas públicas, em regulamentos e em normas de uso geral. Barreiras não explícitas, mas que, na prática, impedem ou dificultam a plena participação das pessoas em vários setores da sociedade); acessibilidade atitudinal (visa uma sociedade sem preconceitos, estigmas, estereótipos e discriminações como resultado de programas e práticas de sensibilização e de conscientização das pessoas em geral e da convivência na diversidade humana).

Partimos do pressuposto de que quando espaços, produtos e processos são pensados para todas as pessoas e não apenas com adaptações destinadas às pessoas com deficiência, os benefícios atingem ampla gama populacional. Para tal, é necessário lançar mão das premissas da acessibilidade plena (SASSAKI, 2003) e do design universal (CAMBIAGHI, 2007; STORY, 2001), de modo a permitir condições de equidade entre pessoas com deficiência e sem deficiência. Além disso, vale ressaltar que, se pensado desde a elaboração do projeto, os custos dispendidos com acessibilidade são baixos, comparados ao valor de adaptações feitas em ambientes, produtos e processos acabados.

Medeiros e Diniz (2004) afirmam que a deficiência é uma experiência resultante da interação entre características corporais do indivíduo e as condições da sociedade em que ele vive, isto é, da combinação de limitações impostas pelo corpo com algum tipo de perda ou redução de funcionalidade a uma organização social pouco sensível à diversidade corporal.

Conforme Diniz (2007), o conceito de deficiência colocado por Medeiros e Diniz (2004) visava superar o modelo biomédico centrado apenas na lesão, no corpo deficiente com alguma doença ou incapacidade. Esse foi o primeiro modelo social da deficiência, defendido pela Upias, como ficou conhecida a Liga dos Lesados Físicos Contra a Segregação. "O argumento do modelo social era o de que a eliminação das barreiras permitiria que os deficientes demonstrassem sua capacidade e potencialidade produtiva" (op. cit., p. 28). Para eles, o 
conceito não exclui as limitações físicas, mentais ou sensoriais que as pessoas possam apresentar, apenas leva em consideração que a sociedade e o ambiente são responsáveis pelo aumento ou pela diminuição dessas características. Quando ambientes, produtos, serviços e processos apresentam condições de acessibilidade à população, a deficiência não será constrangedora ao indivíduo, pois não o impedirá de exercer suas atividades, apesar de não deixar de existir. Da mesma forma, quanto mais deficiente for o ambiente, o produto e o processo, mais as pessoas vão se mostrar deficientes.

Diniz (2007) continua seu argumento apresentando a visão de um segundo modelo social de deficiência, defendido por um viés feminista, que criticava esse primeiro modelo por desprezar a diversidade entre as próprias pessoas com deficiência. Considerava que algumas pessoas, em função do grau das lesões, mesmo no ambiente mais acessível e humanizado, continuarão não podendo exercer suas atividades com autonomia e independência.

As teorias feministas desafiaram não só o tabu do corpo deficiente como, principalmente, a falsa suposição de que todos os deficientes almejariam a independência ou mesmo seriam capazes de experimentá-la como proposto pelos teóricos do modelo social. Com o argumento de que todas as pessoas são dependentes em diferentes momentos da vida, seja na infância, na velhice ou na experiência de doenças, um grupo de feministas introduziu a ideia da igualdade pela interdependência como um princípio mais adequado à reflexão sobre questões de justiça para a deficiência (DINIZ, 2007, p. 29).

Conforme a autora, para as próprias defensoras do modelo feminista havia um receio constante de ocorrer um retrocesso das conquistas obtidas pelas pessoas com deficiência.

O desafio das teóricas do cuidado foi duplo. Por um lado, era preciso superar o
argumento de que a ética caritativa seria revigorada com a emergência do cuidado como
princípio de justiça; por outro, era necessário refutar a tese de que o cuidado substituiria
o projeto de independência. Aos olhos dos teóricos do modelo social, havia uma ameaça
política na defesa do cuidado como garantia de justiça: a de devolver os deficientes ao
espaço da subalternidade e da exclusão social, pois seria mais fácil garantir o cuidado
que modificar a ordem social e política que oprimia os deficientes. Para uma sociedade
pouco sensível aos interesses dos deficientes, o cuidado era um valor com baixo
potencial de subversão da ordem moral (DINIZ, 2007, p. 30 ).

Os argumentos de Diniz (2007) nos fizeram atentar para a diversidade de pessoas com deficiência e as diferentes formas de justiça social para elas. Ponderamos, no entanto, que mesmo para as pessoas que não conseguirão ter independência, devido à sua lesão e deficiência, a acessibilidade integral ainda se faz necessária, na medida em que, mesmo sem autonomia, essas pessoas participam de alguma forma da cidade, mesmo que acompanhadas e/ou cuidadas por outras pessoas. A acessibilidade pode tanto fazer com que uma deficiência "deixe de existir" pela igualdade de condições entre pessoas com e sem deficiência, como auxilia que cuidadores de pessoas sem possibilidade de autonomia tenham mais segurança e conforto na vivência citadina com essas pessoas, cada um em sua realidade. 
Pensar numa cidade que possibilite a convivência de pessoas com deficiência, idosos, crianças, adultos e jovens é ampliar as possibilidades de experiências e trocas socioculturais entre pessoas diversas, em que umas aprendam com as outras, mesmo que não linearmente ou não diretamente a partir do diálogo, mas por algum tipo de convívio.

Para Morigi (2014), dentre os desafios para o alcance da cidade educadora está o de possibilitar uma gestão em que haja coesão social e manutenção de espaços públicos que proporcionem a convivência cidadã com a diversidade.

Essas questões aparecem na análise que Del Pozo (2013) faz das Cartas das Cidades Educadoras frente às mudanças na sociedade nas últimas décadas. Entre as reformulações que as Cartas passaram e incorporaram, desde sua primeira edição em 1990, até sua revisão em 2004, aparecem o reforço de

\begin{abstract}
melhorar e universalizar o acesso de todos, sobretudo daqueles que têm incapacidades funcionais ou quaisquer dependências, a todos os serviços, edifícios e equipamentos urbanos, necessidade principal num contexto de qualificar a convivência urbana. Também se insistiu num aspecto que, por si mesmo e pela evolução das populações, merece consideração: o diálogo e a cooperação inter-geracional, com o fim de atingir a maior integração social possível entre as pessoas de todas as idades e o aproveitamento recíproco dos conhecimentos e experiências vitais" (DEL POZO, 2013, p. 31).
\end{abstract}

Ao ponderar esses desafios, enfatizamos a importância dos espaços urbanos culturais. A apropriação da população, independentemente de suas habilidades ou limitações, a espaços citadinos de cultura reverberam em suas identidades territoriais, contribuindo para que se sintam pertencentes à cidade e, também em função disso, queiram manter esses locais vivos.

Florissi e Valiati (2009) discutem a importância da manutenção dos espaços e bens culturais na cidade à medida que eles traduzem o modo de vida de um povo, agregando manifestações de identidade, valores e crenças da sociedade. A validade de um bem cultural traz benefícios no âmbito econômico e é incomensuravelmente favorável ao bem-estar da sociedade. Miguez (2009) e Yúdice (2004) defendem a cultura como recurso para melhoria social para, a partir de projetos de incremento cultural urbano, alcançar o desenvolvimento urbano sustentável. Assim, os espaços e bens culturais propiciam o usufruto dos espaços e de seu entorno pela população como um todo, reafirmando, a partir do lugar de convívio, valor e identidade às pessoas e a propagação de seus aspectos socioculturais.

Porém, ainda que corroboremos com Florissi e Valiati (2009), Miguez (2009) e Yúdice (2004) e defendamos a importância da cultura na vivência citadina, questionamos: como se dá a efetiva possibilidade de participação das pessoas com deficiência na manutenção, fruição e disseminação da cultura no Brasil? Os espaços culturais das cidades brasileiras possibilitam a 
participação de pessoas com deficiência? Como a falta de participação dessas pessoas na cidade implica na nossa cidadania?

Dorneles et al. (2018) fazem um histórico sobre a acessibilidade cultural no Brasil. As autoras analisam que, até 2008, quando foi realizada a Oficina de Políticas Públicas de Cultura para Pessoas com Deficiência, promovida pelo então Ministério da Cultura (MinC), a acessibilidade cultural se limitava apenas à perspectiva econômica, ofertando ingressos com preços menores ou gratuitamente a espetáculos e projetos vinculados à Lei Rouanet.

\begin{abstract}
Sabe-se que a referida oficina se tornou um marco importante na pauta da acessibilidade cultural para as pessoas com deficiência. A oficina, realizada em 2008, mesmo ano em que o Brasil se torna signatário da Convenção dos Direitos das Pessoas com Deficiência, é um resultado dos compromissos do MinC, junto a uma demanda latente da sociedade civil que atuava no período no campo da produção e difusão artística e cultural das pessoas com deficiência. A iniciativa de estruturar uma política para este segmento cultural refletia-se também com o compromisso do Minc e do Estado brasileiro em relação à Convenção da Proteção e Promoção das Expressões da Diversidade Cultural, realizada em 2005 pela UNESCO, do qual o Brasil se torna signatário no mesmo ano (DORNELES et al., 2018, p. 146).
\end{abstract}

Conforme as autoras, a oficina possibilitou "construir ações e diretrizes para a política nacional de cultura que envolvesse a temática da difusão, fomento, patrimônio da proteção estética, artística e cultural para pessoas com deficiência” (DORNELES et al., 2018, p. 146). Contribuiu para ultrapassar a perspectiva apenas da acessibilidade física do espaço e para atingir o objeto cultural. Além de resultar na "ampliação e fortalecimento do debate sobre o tema e o direito da cidadania cultural da pessoa com deficiência nas conferências municipais, estaduais e nacional de cultura" (DORNELES et al., 2018, p. 146), ampliando a possibilidade de efetivação das ações.

\title{
PROCEDIMENTOS METODOLÓGICOS
}

Para atingir os objetivos pretendidos, desenvolvemos pesquisas descritivas e qualitativas (GIL, 2002), a partir de análises bibliográficas e documentais. Os temas pesquisados versaram, principalmente, sobre a questão do direito à cidade e suas interrelações culturais, sociais, educacionais, políticas e espaciais; aspectos relacionados às pessoas com deficiência, acessibilidade plena e design universal, bem como esses aspectos interferem na vivência da cidade; políticas públicas com foco, principalmente, na cultura e no lazer e em suas relações com a educação, entendida para além apenas da escola, buscando o tema das cidades educadoras. Todos esses temas foram analisados à luz dos direitos humanos e da consolidação da cidadania. 


\section{RESULTADOS E ANÁLISES}

A diversidade e a pluralidade fazem parte da vida humana. A possibilidade de trocas sociais na cidade por pessoas diferentes, no âmbito físico, antropométrico, de gênero, de idade, de classes e de culturas, faz com que, potencialmente, umas possam aprender com as outras.

Vale ressaltar que essas trocas e esses processos de aprendizagem não são necessariamente lineares nem diretos, muito menos acontecem, basicamente, a partir de diálogos. É o enriquecimento da vida urbana, a possibilidade de saber da existência de uma pessoa diferente de si e do modo de ser e de estar no mundo de forma distinta da sua, que podem gerar reflexões.

Nesse mesmo sentido, o próprio conceito de identidade depende do conhecimento do outro. Castells (2013), Laraia (2011) e Woodward (2000) concordam que a identidade diz respeito à relação com o outro identificado como diferente de si. Ou seja, ser identificado como brasileiro, por exemplo, significa não ser francês, não ser inglês, não ser sul-africano e assim por diante. Castells (2013, p. 22) entende por "identidade a fonte de significado e experiência de um povo". Assim, conforme Woodward (2000), a construção da identidade é tanto simbólica quanto social, e a luta para afirmar uma ou outra identidade ou as diferenças que as cercam tem causas e consequências materiais. Portanto, a possibilidade de trocas entre pessoas diversas reforça aspectos de identidade e diferença, assim como promove potenciais câmbios culturais e educacionais a partir dessas relações, sejam físicas, visuais ou de outras formas.

Um dos pilares da cidadania está relacionado ao convívio em bem-estar com a diversidade e a pluralidade sociais. A possibilidade de usufruto da cidade por pessoas diversas contribui para promover a troca de experiências entre elas e entre elas e a cidade. Assim, o direito à cidade se faz necessário para promover essas trocas, e esse direito à cidade não pode continuar sendo mais negado ainda às pessoas com deficiência.

A retroalimentação entre acessibilidade, direito à cidade e cidade educadora se dá na construção diária e cotidiana de vidas dignas, de subjetividades possíveis, de diversidades respeitadas, de vozes ouvidas e de demandas alcançadas. Para isso, ponderamos que o primeiro passo rumo à cidade educadora é possibilitar pleno acesso aos espaços da cidade, principalmente, àqueles relacionados a cultura, arte, educação e lazer. As melhorias propiciadas às pessoas com deficiência, nos termos da acessibilidade plena e do design 
universal, tendem a melhorar o usufruto dos espaços para toda a população, gerando mais conforto e segurança.

Buscamos o estudo do direito à cidade via os espaços culturais urbanos na tentativa de caminhar rumo a construção de uma cidade educadora porque entendemos a potência da cultura na vida das pessoas e, mais ainda, o estrago que a falta de cultura traz à sociedade. Domingues e Albinati (2017, p. 112) lembram que "o espaço físico (espaço construído, modificado) é muitas vezes resultado de cerceamentos de direitos e de negação de possibilidades múltiplas de experimentação", decorrentes das relações de poder embutidas no conjunto de práticas sociais que operam no espaço, sendo "essencial pensar como as análises da relação entre política e cultura precisam ser elaboradas" considerando essas disputas de forças.

Pimentel e Pimentel (2017) discutem a importância da acessibilidade, do design universal e das tecnologias assistivas como condições sine qua non para inclusão social, educacional e cultural, entendidas como direito de cidadãos brasileiros com alguma deficiência. Apontam que, para se alcançar uma sociedade inclusiva e igualitária, é necessário que toda a sociedade e a justiça permaneçam atentas para que os direitos conquistados sejam mantidos e cumpridos e, cada vez mais, ações sejam tomadas para que espaços públicos, educacionais, de lazer, saúde e cultura se tornem acessíveis a todos, como direitos sociais.

A partir de nossas análises bibliográficas e documentais, encontramos exemplos de inclusão social relacionando cultura, educação de modo holístico e pessoas com deficiência. Como apontado por Dorneles et al. (2018), quando falamos de acessibilidade cultural para pessoas com deficiência, não basta pensar apenas na acessibilidade física. As pessoas com deficiência devem ter a possibilidade de ser agentes culturais, como qualquer outra pessoa.

Barrozo et al. (2012), ao refletirem sobre as questões da inclusão e acessibilidade para as pessoas com deficiência no esporte, cultura e lazer, defendem que acessibilidade não se trata apenas de entrar em um ambiente, mas sim do direito de participar ativamente no meio, de ter acesso à cidadania e à inclusão. Entendem a necessidade de pessoas com deficiência participarem de vários grupos sociais. Evidenciam que a cultura, o esporte e o lazer têm papel fundamental nesse processo, pois "vão além da promoção da qualidade de vida ou bem-estar. São meios pelos quais o sujeito se desenvolve e exerce sua cidadania, além de se apropriar do seu espaço físico e social" (op. cit., p. 26).

Anversa (2012) questiona o motivo do distanciamento de pessoas com deficiência em ambientes culturais. Analisa que a dificuldade de inclusão dessas pessoas se dá mais pela falta 
de oferta de atividades culturais inclusivas, do que pelo tipo de deficiência em si. Pondera ser um desafio inserir pessoas com deficiência em espaços culturais, devido a não adequação desses ambientes, tanto para a locomoção quanto para o oferecimento de métodos facilitadores, como a mediação.

Silva (2016), ao analisar a acessibilidade para pessoas com deficiência visual em três museus de Belo Horizonte-MG, aponta que é preciso refletir sobre a implantação de ambientes acessíveis, desde a entrada até o interior do edifício, e promover práticas educativas de acordo com as especificidades dos sujeitos que visitam os espaços culturais, a fim de favorecer e fomentar a acessibilidade nos museus para sujeitos cegos ou com baixa visão.

Gomes e Chalhub (2017) analisaram a experiência e a percepção dos estudantes de pedagogia surdos e ouvintes do INES - Instituto Nacional de Educação de Surdos, após visitação à Casa da Ciência da UFRJ e ao Museu das Telecomunicações Oi Futuro. Visaram dialogar e discutir como as estratégias de acessibilidade podem mediar e favorecer a prática pedagógica e a formação dentro desses espaços, e como foi a aquisição de informação por meio de experiências diversas de acessibilidade. Relataram que, no primeiro caso, contaram com auxílio de dois profissionais do próprio INES para fazer a mediação entre alunos surdos e mediadores da UFRJ. O formato da exposição, com pouca informação textual e muita informação visual, através de fotos, maquete, vídeos legendados, animações legendadas e um vídeo guia em Libras apresentando o conteúdo, contribuiu para a apreensão pelos alunos. A visita ao Oi Futuro foi guiada por um mediador surdo e uma intérprete ouvinte contratados pelo próprio centro cultural, o que facilitou a comunicação e manteve os alunos constantemente interessados na exposição.

Para as autoras, a experiência em espaços não escolares com alunos surdos, como estratégia para dinamizar a aprendizagem e aprofundar questões discutidas em sala de aula, tem se mostrado profícua. Advertem que se faz "urgente o investimento na formação de profissionais para o trabalho na mediação e atendimento aos surdos nos diferentes espaços culturais" (GOMES; CHALHUB, 2017, p. 13). A partir de suas experiências de visitações anteriores, em outros museus e espaços não escolares, observaram que "a falta desses profissionais acarreta o menor envolvimento dos estudantes surdos com a exposição e recursos oferecidos" (op. cit., p. 13).

Cabe ressaltar também que o pleno acesso, o direito de participar dos espaços perpassa por uma condição de autonomia para a pessoa. No caso de acesso e fruição de pessoas com deficiência a espaços culturais, estudos (GOMES; CHALHUB, 2017; SOUZA et al., 2017; 
SILVA, 2016) mostram que a sociedade busca medidas paliativas, isto é, representadas pela figura do mediador. É preciso propor um ponto de vista diversificado, que permita pensar espaços múltiplos, não apenas adaptados ou com a presença de intermediários, mas sim espaços projetados com design universal (CAMBIAGHI, 2007; STORY, 2001), que possam oferecer uma experiência amplamente acessível, atendendo à diversidade populacional e possibilitando interação para quem tem ou não alguma deficiência.

Mattos et al. (2019), ao refletirem sobre a acessibilidade em ambientes culturais, a partir de análise qualitativa de um museu, do seu ambiente, de seu acervo e de suas funcionalidades, pensando nas peculiaridades de pessoas com deficiência visual e com transtorno do espectro autista, perceberam que o local apresenta diversas barreiras a essas pessoas. Mesmo com a implantação de diversas propostas inclusivas em seu acervo, o local necessita de uma reorganização mais específica para atendê-las, observando a importância de se adaptar e reinventar suas práticas para abarcar demandas específicas das pessoas com deficiência.

Os estudos de Souza et al. (2017) sinalizam para a importância da acessibilidade cultural aos espaços urbanos livres públicos. Os autores descrevem uma experiência de aplicação do recurso de audiodescrição a um city tour na cidade de Pelotas-RS, organizado para pessoas com deficiência. Além da relevância da acessibilidade comunicacional, afirmam que objetivaram

ampliar o diálogo e a participação do público, principalmente as pessoas com deficiência, com o objeto cultural por meio de estratégias de mediação que possibilitem que todos os públicos consigam compreender os conteúdos apresentados e, assim, alcancem o direito de se reconhecerem como parte do patrimônio cultural (SOUZA et al., 2017, p. 144).

Assim como Souza et al. (2017) indicam a importância das pessoas se reconhecerem em sua cultura, Ribeiro et al. (2012) defendem que a acessibilidade física pode atuar como agente de preservação em ambientes reconhecidos como patrimônio cultural, por oportunizar acesso, uso e apropriação cultural a mais pessoas, aumentando o interesse de maior parcela da população em conservá-los. As autoras apontam que é possível inserir intervenções contemporâneas com vistas à melhoria da acessibilidade desses espaços e edificações, sem prejudicar as características que fazem com que sejam entendidos como espaços históricoculturais. Para tal, é preciso evidenciar as diferenças entre as intervenções contemporâneas e o espaço "original". Apresentam exemplos nacionais e internacionais de espaços considerados patrimônios culturais que alcançaram a acessibilidade física sem prejudicar seus valores históricos e culturais. Advertem, entretanto, que ainda há muito a ser feito para evitar a 
segregação das pessoas com deficiência a vários desses locais, uma vez que, além das barreiras, ainda existe uma série de rótulos e preconceitos que reforçam a discriminação.

É preciso ponderar a necessidade ainda latente de entender que a acessibilidade plena só se concretizará quando for pensado o sistema como um todo; não apenas um espaço público ou uma edificação. É preciso dar condições dignas às pessoas com deficiência vivenciarem a cidade em sua amplitude: percorrer ruas e demais espaços citadinos, se deslocar pela cidade em transporte público, acessar e interagir no e com o local de destino. E, mais do que simplesmente conseguir transpor esses caminhos, é fundamental que isso se dê com conforto, segurança e autonomia.

As cidades brasileiras estão repletas de espaços que se dizem acessíveis, mas essa acessibilidade, muitas vezes, depende de um mediador. As atividades cotidianas nesses lugares obedecem a essa dependência, seja para abrir uma porta específica, colocar uma rampa, usar uma plataforma inclinada ou oferecer orientação; e quando a pessoa responsável por essa tarefa não está no local, não há mais acessibilidade.

$\mathrm{Na}$ cidade do Rio de Janeiro, por exemplo, há várias estações de metrô em que a acessibilidade depende de um mediador que, normalmente, são seguranças, para auxiliar as pessoas com deficiência a transpor as barreiras, como escadas. Fica evidente a desigualdade no período estimado da viagem, se comparado ao tempo do trajeto feito por uma pessoa que não demanda essa "acessibilidade". Ao consultarmos o site do Metrô Rio (2019), pudemos perceber que das 41 estações de metrô da cidade, apenas 28 estações dispõem de elevador. Dentre essas, há algumas em que o elevador não leva a todos os níveis da estação, como é o caso, por exemplo, das estações Cardeal Arcoverde e Botafogo. Nossas análises vão ao encontro da pesquisa de Wasowski et al. (2016).

Wasowski et al. (2016), em um estudo sobre as estações de metrô do Rio de Janeiro, verificaram diversos dificultadores de mobilidade para deficientes, entre eles barreiras como níveis com acesso apenas por escadas, falhas estruturais nas obras de adaptação, como nos pisos táteis, e ausência de manutenção da estrutura disponível. Concluíram que:

\footnotetext{
Mesmo que uma estação possa ser acessível, não significa que é conveniente [para pessoas com deficiência] usar as acomodações do transporte. Por exemplo, a estação do metrô de Botafogo tem seis entradas, aparentemente muito conveniente para os passageiros, a menos que o passageiro exija o uso do elevador. Conforme indicado no mapa, o elevador está perto da entrada "A" e fica diretamente ao lado de uma rua de mão única; os clientes precisam percorrer as ruas no entorno da estação para ter acesso ao elevador. (...) Embora o sinal indique que os clientes podem pegar o elevador no andar da plataforma, esta equipe de pesquisa não conseguiu encontrar, nesse nível, o acesso ao elevador (WASOWSKI et al., 2016, p. 21, tradução livre).
} 
Apesar de existir ampla legislação amparando os direitos das pessoas com deficiência no Brasil, constrangimentos, barreiras e/ou dificultadores de mobilidade e integração, como os discutidos ao longo deste texto, com base nas pesquisas bibliográficas realizadas, indicam que pessoas com deficiência têm menos oportunidades de vivenciar a cidade do que aquelas sem deficiência. Logo, menos possibilidade de trocar informações com a urbe e a partir dela, com seus habitantes, signos, símbolos e aspectos socioculturais. Entre outros direitos negados, têm menos acesso a lugares públicos de convivência, ao lazer, ao esporte, a espaços culturais, ou seja, menos oportunidades educacionais.

Essas ponderações nos levam a recordar a argumentação que Canclini (2015) faz acerca da institucionalização do patrimônio cultural. O autor pondera sobre o rebatimento das relações de poder em várias esferas da vida pública e social, refletindo, entre outros, na naturalização do que deve ser preservado e propagado para constituir a identidade de um país. A partir de suas pesquisas, Canclini avalia que alguns bens, tais como as pirâmides maias, palácios coloniais e coleções de cerâmicas indígenas seculares, são naturalizadas como algo a ser preservado e multiplicado para as gerações futuras, por simbolizar prestígio do passado que se liga às questões de identidade nacional. "A perenidade desses bens leva a imaginar que seu valor é inquestionável e torna-os fontes de consenso coletivo, para além das divisões de classes, etnias e grupos que cindem a sociedade e diferenciam os modos de apropriar-se do patrimônio" (CANCLINI, 2015, p. 160). Essa distinção reforça as diferenças entre classes sociais, que determina quais bens devem ser representativos, aqueles que agradem a uma determinada classe, geralmente, a de maior poder econômico e social.

Nesse sentido, conforme Canclini (op. cit.), quanto mais desce o nível educacional da população, menos as pessoas se reconhecem no patrimônio cultural institucionalizado, pois, não tendo oportunidade de usufruir do mesmo, não o reconhece como seu. Afinal, como conceber um espaço como seu patrimônio sem ter a oportunidade de conhecê-lo e vivenciá-lo?

Ainda que a discussão feita por Canclini (2015) se dê, principalmente, a respeito de classes sociais, fazemos essa mesma relação pensando nas pessoas com deficiência, em razão das oportunidades de acesso e usufruto aos bens e espaços culturais. Assim como as pessoas de classes sociais mais baixas, como discutido por Canclini, se as pessoas com deficiência não têm as mesmas oportunidades de acesso e usufruto da educação e cultura propiciada e compartilhada na e pela cidade, como podem se reconhecer como partes integrantes dessa cidade, como reconhecer algo com valor histórico e cultural, se não lhes dão oportunidade de interagir com tais bens, edificações e espaços? Pensando nas disputas de 
forças verticais e horizontais na disputa citadina, apontadas por Santos $(2009,2001)$, em que a cultura também está inserida, e nas discussões feitas por Ribeiro et al. (2012) da acessibilidade física poder ser motor de preservação e propagação cultural, defendemos que a educação e o acesso são fatores preponderantes desse reconhecimento e apropriação.

A partir do espaço construído, mantido e em constante transformação pelos seres humanos é que se desenvolve o processo da cultura. Segundo Arantes (2012), na vivência citadina é possível realizarmos constantemente, no dia a dia, operações mentais de codificação e decodificação de mensagens que requerem o conhecimento desses significados implícitos nas ações e nos objetos, e de suas regras tácitas. Os significados culturais não são compreendidos através da contemplação passiva do objeto significante, mas como referência ao universo de significados próprios de cada grupo social.

Essa referência ao universo de significados pertencentes a cada grupo social é o que White (2009) chama de simbologização, sendo esta capacidade intrínseca à cultura. Simbologizar é "a capacidade de originar, definir e atribuir significados, de forma livre e arbitrária, a coisas e acontecimentos no mundo externo, bem como compreender esses significados" (WHITE, 2009, p. 9). Estes não podem ser percebidos e avaliados a partir dos cinco sentidos humanos (tato, olfato, paladar, audição e visão); envolve o processo de aprendizado construído a partir da experiência de certa sociedade com tal aspecto simbologizado, podendo ser um objeto, um espaço, um ato, uma crença. "Portanto, envolve a possibilidade de criar, atribuir e compreender significados" (p. 9). Para isso, é fundamental o contato e a vivência com os diversos aspectos.

Retirar a possibilidade de a população se apropriar de seu território, de sua cidade, de seu poder de atuação na sociedade é lhe negar o direito à vivência de sua cultura, é negar o direito à cidade. É negar o direito à busca por melhores condições de vida. É negar seu poder de cidadão. As pessoas com deficiência precisam simbologizar suas existências e significâncias na vida citadina, na esfera sociocultural e ter oportunidade de voz, de construir a cidade que almejam e poder propagar suas vivências, sua cultura. 


\section{CONSIDERAÇÕES FINAIS}

Para efetivamente vivenciar a cidadania, é imprescindível a participação das pessoas na cidade e nas decisões de que cidade almejam. O direito à cidade é a efetivação da cidadania. No caso das pessoas com deficiência, esse direito é exercido com mais dificuldades, em função das condições de acessibilidade das cidades, ou, no caso, da falta dela.

Ao focar na Baixada Fluminense, periferia do Rio de Janeiro, vemos as dificuldades de forma mais evidente e percebemos o quanto elas impactam não somente às pessoas com deficiência, como à sociedade em geral. Quando as pessoas não têm acesso aos espaços citadinos, não conseguem trocar informações com tudo que envolve as cidades e as pessoas que as compõem, diminuindo a construção do conhecimento cotidiano individual e coletivo.

Por isso, é importante pensar um conceito de cultura amplo, que seja capaz de abarcar os debates da inclusão e participação social. Considerando que o convívio e a participação em grupos e circuitos sociais também fazem parte da acessibilidade plena, podemos afirmar que o direito à cidade se estabelece justamente na participação efetiva e política dos grupos sociais da e na cidade. Enxergar que a cultura atravessa as relações e a cotidianidade é fundamental para entender o papel de mediação social da cultura, da educação e do lazer, sendo esses aspectos estratégicos para a inclusão de pessoas com deficiência.

Em tempos de isolamento social em prevenção ao novo coronavírus, podemos perceber mais facilmente como é importante, quando esse período passar, voltar a poder militar pelo reforço da vivência na e da cidade, mesmo que, às vezes, essa conquista pareça ser utópica. Quando não podemos vivenciar os espaços urbanos, deixamos de trocar informações com eles, com as pessoas que circulam nas ruas, com as edificações, com as placas de trânsito, com as placas de propaganda, com as regras implícitas em cada espaço de convivência, em tudo que envolve a formação cidadã pelo encontro com o diferente de si.

Estes tempos nos mostram, em alguma medida, como é viver em cidades não preparadas para receber e abarcar pessoas com deficiência. Já que, na tentativa de diminuir a propagação do vírus, neste momento, o isolamento social de toda a população se faz necessário; mas, no caso das pessoas com deficiência, mesmo em tempos "normais", são forçadas a viver mais isoladas porque não conseguem vivenciar os espaços citadinos com conforto, segurança e independência, da mesma forma que as pessoas sem deficiência. Estamos sentindo a falta que a convivência citadina faz ao bem-estar não apenas físico, como também social e mental. 


\section{REFERÊNCIAS}

AICE - Associação Internacional das Cidades Educadoras. Carta das cidades educadoras. Disponível em http://www.edcities.org/pt/carta-das-cidades-educadoras/ Acesso em 13/04/19 às $19 \mathrm{~h} 14 \mathrm{~min}$.

AIETA, Vânia Siciliano; ZUIN, Aparecida Luzia Alzira. Princípios Norteadores da Cidade Educadora. Revista de Direito da Cidade, v.04, n. 02, p. 193-232, 2012.

ANVERSA, Priscila. Família e museu de arte: a acessibilidade de pessoas com deficiência nos espaços expositivos. Palíndromo, v. 4, n. 7, p. 133-150, 2012.

ARANTES, Antonio Augusto. O que é cultura popular. 14. ed. 10. reimp. São Paulo: Brasiliense, 2012.

ATLAS BRASIL. Atlas de Desenvolvimento Humano no Brasil, 2013. Disponível em http://www.atlasbrasil.org.br/2013/pt/ Acesso em 19/05/20 às 14h04min.

BARROZO, Amanda Faria; HARA, Ana Clara Portela; VIANNA, Daniela Carrogi; OLIVEIRA, Juliana de; KHOURY, Laís Pereira; SILVA, Priscila Ludovico da; SAETA, Beatriz Regina Pereira; MAZZOTTA, Marcos José da Silveira. Acessibilidade ao esporte, cultura e lazer para pessoas com deficiência. Cadernos de Pós-Graduação em Distúrbios do Desenvolvimento, São Paulo, v.12, n.2, p. 16-28, 2012.

CAMBIAGHI, Silvana. Desenho Universal: métodos e técnicas para arquitetos e urbanistas. São Paulo: Senac, 2007.

CASTELLS, Manuel. O poder da identidade - Volume II. Tradução: Klauss Brandini Gerhardt. 8. ed. 7. reimp. São Paulo: Paz e Terra, 2013.

CANCLINI, Néstor Garcia. Culturas Híbridas: Estratégias para Entrar e Sair da Modernidade. Tradução: Heloísa Pezza Cintrão, Ana Regina Lessa; tradução da introdução: Gênese Andrade. 4. ed. 7. reimp. São Paulo: Editora da Universidade de São Paulo, 2015.

CERTEAU, Michel de. A invenção do cotidiano: 1. Artes de fazer. 15. ed. Tradução Ephraim Ferreira Alves. Petrópolis: Vozes, 2008.

DEL POZO, Joan Manuel. O conceito de "cidade educadora", hoje. In: AICE - Associação Internacional de Cidades Educadoras (Org.). Educação e vida urbana: 20 anos de Cidades Educadoras. Torres Novas: UNESCO, 2013.

DINIZ, Débora. O que é deficiência. Coleção Primeiros Passos. 1. ed. São Paulo: Brasiliense, 2007.

DOMINGUES, João; ALBINATI, Mariana. Direitos culturais: diversidade e conflito produzindo a cidade. In: SANTOS JUNIOR, Orlando Alves dos et al. (Orgs.). Políticas públicas e direito à cidade: programa interdisciplinar de formação de agentes sociais. Rio de Janeiro: Letra Capital, 2017. 
DORNELES, Patrícia Silva; CARVALHO, Claudia Reinoso Araujo de; SILVA; Ana Cecília Chaves; MEFANO, Vânia. Do direito cultural das pessoas com deficiência. Revista de Políticas Públicas, v. 22, n. 1, p. 138-153, 2018

FLORISSI, Stefano; VALIATI, Leandro. Construção de lugares de consumo e práticas culturais. In: CRIBARI, Isabela. (Org.). Economia da cultura. Recife: Fundação Joaquim Nabuco/Massangana, 2009.

GALEANO, Eduardo. Las palabras andantes. Colección Biblioteca Eduardo Galeano. Tres Cantos: Siglo XXI Editores, 1998.

GEERTZ, Clifford. Atrás dos fatos: dois países, quatro décadas, um antropólogo. Tradução: Denise Jardim Duarte. Petrópolis, RJ: Vozes, 2012.

GIL, Antonio Carlos. Como Elaborar Projetos de Pesquisa. 4. ed. São Paulo: Editora Atlas, 2002.

GOMES, Marisa da Costa; CHALHUB, Tânia. REFLEXÕES E PRÁTICAS: percepções de alunos surdos e ouvintes em relação à visitação de museus no contexto de um curso de formação de professores. In: Encontro Nacional de Acessibilidade Cultural, V. Anais. Rio de Janeiro: V ENAC, 2017.

HAESBAERT, Rogério. Identidades territoriais: entre a multiterritorialidade e a reclusão territorial (ou: do hibridismo cultural à essencialização das identidades). In: ARAUJO, Frederico Guilherme Bandeira; HAESBAERT, Rogério (Orgs.). Identidades e territórios: questões e olhares contemporâneos. Rio de Janeiro: Access, 2007.

IBGE - INSTITUTO BRASILEIRO DE GEOGRAFIA E ESTATÍSTICA. Censo Demográfico 2010: características gerais da população, religião e pessoas com deficiência. Rio de Janeiro: IBGE, 2012.

LARAIA, Roque de Barros. Cultura: um conceito antropológico. 24. reimp. Rio de Janeiro: Zahar, 2011.

LEFEBVRE, Henri. O direito à cidade. Tradução: Rubens Eduardo Frias. 5. ed. 2. reimp. São Paulo: Centauro Editora, 2010.

MATTOS, Michele Morgane de Melo; MACHADO, Sídio Werdes de Sousa; VIEIRA, Cristiane Rodrigues; BRAZ, Ruth Maria Mariani; LIONE, Viviane de Oliveira Freitas. (Re)Pensando a Acessibilidade em Ambientes Culturais para Pessoas com Deficiência Visual e Transtorno do Espectro Autista. Revista Educação, Artes e Inclusão, v. 15, n. 14, out/dez, 2019.

MEDEIROS, M.; DINIZ, D. Envelhecimento e deficiência. SérieAnis 36, Brasília, LetrasLivres, p. 1-8, junho, 2004.

METRÔ RIO. Acessibilidade das estações. Disponível em https://www.metrorio.com.br/GuiaDoCliente/Acessibilidade\# Acesso em 20/05/20, às 23h23min. 
MIGUEZ, Paulo. Aspectos de constituição do campo de estudos em economia da cultura. In: CRIBARI, Isabela. (Org.). Economia da cultura. Recife: Fundação Joaquim Nabuco/Massangana, 2009.

MORIGI, Valter. Cidades educadoras: possibilidades de novas políticas públicas para reinventar a democracia. Tese (Doutorado em Educação). Programa de Pós-Graduação em Educação, Faculdade de Educação, Universidade Federal do Rio Grande do Sul. Porto Alegre: UFRGS, 2014.

PIMENTEL, Susana Couto; PIMENTEL, Mariana Couto. Acessibilidade para inclusão da pessoa com deficiência: sobre o que estamos falando? Rev. FAEEBA - Ed. e Contemp., Salvador, v. 26, n. 50, p. 91-103, set./dez. 2017.

PORTAL BRASIL. Expectativa de vida no Brasil sobe para 75,5 anos em 2015. 01/12/2016. Disponível em http://www.brasil.gov.br/governo/2016/12/expectativa-de-vida-no-brasil-sobepara-75-5-anos-em-2015 Acesso em 17/03/17 às 09h59min.

RIBEIRO, Gabriela Sousa; MARTINS, Laura Bezerra; MONTEIRO, Circe Maria Gama. O desafio da acessibilidade física diante da sacralização do patrimônio histórico e cultural. Cadernos PROARQ, n. 19, p. 131-151, dez./2012.

SANTOS, Milton. A Natureza do Espaço: Técnica e Tempo, Razão e Emoção. 4. ed. 5. reimpr. São Paulo: Editora da Universidade de São Paulo, 2009.

SANTOS, Milton. Por uma outra globalização: do pensamento único à consciência universal. 6. ed. Rio de Janeiro: Record, 2001.

SASSAKI, Romeu. Inclusão no lazer e no turismo: em busca da qualidade de vida. São Paulo: Áurea, 2003.

SILVA, Kátia Ariane. Acessibilidade para deficientes visuais: um estudo nos museus de Belo Horizonte. Revista Temas em Educação, João Pessoa, v.25, n. 1, p.91-113, jan.-jun. 2016.

SOUZA, Ellen; PEREIRA, Leandro Freitas; DEGASPERI, Maria Helena. Ver sem olhar: Acessibilidade cultural em uma Pelotas inclusiva. In: Encontro Nacional de Acessibilidade Cultural, V. Anais. Rio de Janeiro: V ENAC, 2017.

STORY, M. F. Principles of Universal Design. In: PREISER, W. F. E.; OSTROFF, E. Universal Design Handbook. 1. ed. Estados Unidos: Mc Graw Hill, 2001.

UNIC RIO - Centro de Informação das Nações Unidas para o Brasil. Declaração Universal dos Direitos Humanos. Rio de Janeiro: UNIC, 2009. Disponível em https://nacoesunidas.org/direitoshumanos/ Acesso em 28/03/2020 às 21h11min.

VAZ, Lilian Fessler; SELDIN, Cláudia; AVILEZ, Carlos Rodrigo. Notas sobre a experiência de uma política pública integrada: o caso do Bairro-Escola em Nova Iguaçu. In: Tamara Tania Cohen Egler; Hermes Magalhães Tavares. (Org.). Política pública, rede social e território. 1ed. Rio de Janeiro: Letra Capital, 2012. 
WASOWSKI, Richard; MOORE, Alexa; BORTON, Austin; ELLIS, Brendon Matheus; HENDERSHOTT, Kearsten; ELLIS, Jason Brent; ABREU-ELLIS, Carla Reis. Accessibility in Metrô Rio prior to the 2016 Olympic and Paralympic Games. Teoria Jurídica Contemporânea, v. 1, n. 1-2, p. 6-35, jul-dez./2016.

WHITE, Leslie A. O conceito de cultura. Tradução: Teresa Dias Carneiro. Rio de Janeiro: Contraponto, 2009.

WOODWARD, Kathryn. Identidade e diferença: uma introdução teórica e conceitual. In: SILVA, Tomaz Tadeu da (Org.). Identidade e diferença: a perspectiva dos estudos culturais. Petrópolis: Vozes, 2000.

YÚDICE, George. A Conveniência da cultura: usos da cultura na era global. Belo Horizonte: UFMG, 2004. 